\title{
Iron (III) Chloride Catalyzed Claisen Rearrangement Reaction of Allyloxyarenes under Microwave Conditions
}

\author{
Indah Nur Pramesti, Yutaka Okada* \\ Department of Applied Chemistry, Ritsumeikan University, Shiga, Japan \\ Email: ygvictor@sk.ritsumei.ac.jp
}

\author{
How to cite this paper: Pramesti, I.N. and \\ Okada, Y. (2017) Iron (III) Chloride Cata- \\ lyzed Claisen Rearrangement Reaction of \\ Allyloxyarenes under Microwave Condi- \\ tions. Green and Sustainable Chemistry, 7, \\ 234-245. \\ https://doi.org/10.4236/gsc.2017.73018 \\ Received: July 20, 2017 \\ Accepted: August 22, 2017 \\ Published: August 25, 2017 \\ Copyright $\odot 2017$ by authors and \\ Scientific Research Publishing Inc. \\ This work is licensed under the Creative \\ Commons Attribution International \\ License (CC BY 4.0). \\ http://creativecommons.org/licenses/by/4.0/
}

\begin{abstract}
The Claisen rearrangement is a [3,3]-sigmatropic rearrangement which is an important method for new $\mathrm{C}-\mathrm{C}$ bond formation in organic synthesis. This reaction is a typical thermal reaction that requires a high temperature and long reaction time. In this paper, the acceleration effects of the iron (III) chloride $\left(\mathrm{FeCl}_{3}\right)$ catalyst and microwave irradiation during the Claisen rearrangement reaction of allyloxyarene derivatives are reported. The $\mathrm{FeCl}_{3}$ catalyst was able to initiate the reaction at low temperature and induced the subsequent cyclization reaction. The moderation of excellent yields was obtained in a short reaction time. The formation of complex ferric-arenes under microwave irradiation conditions to efficiently absorb the microwaves was expected and confirmed.
\end{abstract}

\section{Keywords}

$\mathrm{FeCl}_{3}$, Claisen Rearrangement, Allyloxyarenes, Microwave Irradiation Effect

\section{Introduction}

Presently, several environmental problems such as global warming and pollution caused by an industrial process become the world concern. Regarding to the considerable impact of environmental problems, the production of chemicals using the principles of green chemistry is extensively studied. The environment-friendly reaction becomes the main topic in organic synthesis.

Since discovered in 1912, the Claisen rearrangement reaction has been developed into one of the most powerful C-C bond forming methods in organic synthesis [1]. This reaction normally takes place by heating the O-allyl ether of phenols or enols, thus forming the C-allyl compound. In general, the Claisen rear- 
rangement of allyloxyarenes is typically performed with a long reaction time in the high temperature range of $180^{\circ} \mathrm{C}-225^{\circ} \mathrm{C}$ [2]. Therefore, it is necessary to develop milder reaction conditions which are efficient and moreover provide an environment-friendly reaction.

A large amount of the Lewis acid is attempted to catalyze the Claisen rearrangement reaction. The Lewis acid has been reported as having the properties that can form transition metal complexes that promote and facilitate the intramolecular rearrangement [3] [4]. However, many catalysts are derived from heavy or rare metals that are toxic and of too high a cost for large-scale applications. The $\mathrm{FeCl}_{3}$ catalyst has attracted considerable attention as a desirable catalyst due to its low cost, ease of use and environmental friendly properties [5].

On the other hand, it is known that a directly heating method is conventionally used as the heating source for organic reactions. Because these methods depend on convection currents and the relatively low thermal conductivity of the reaction mixtures, it would be an inefficient way of transferring heat to the sample [6]. Recently, microwave irradiation has been demonstrated to be a powerful tool for organic synthesis since it offers significant advantages over conventional heating, e.g., cleaner method, quick reaction, high chemical yield, and high selectivity. The microwaves can directly heat the sample by involving the interaction of molecules in the sample with the electric field of the microwave irradiation [7] [8]. In this study, the microwave heating effects on the Claisen rearrangement reaction of allyloxyarene derivatives in the presence of the $\mathrm{FeCl}_{3}$ catalyst were investigated.

\section{Experimental}

\subsection{Claisen Rearrangement Reaction}

This study used four observation materials. The substrate allyloxybenzene (1a) was obtained from commercial sources (WAKO Chemical Ltd.). The substrates 1-allyloxynaphthalene (2a), 1-crotyloxynaphthalene (3a) and 1-cinnamyloxynaphthalene (4a) were synthesized based on a previous report [9]. The Claisen rearrangement was performed by mixing the substrate, e.g., 1a, 2a, 3a, 4a $(0.5$ $\mathrm{mmol}), \mathrm{FeCl}_{3}$ catalyst (0.15 molar ratio) and the solvent including 1,2-dichloroethane and decalin $\left(7 \mathrm{~cm}^{3}\right)$ in a test tube. The usage of 1,2-dichloroethane representing as a low polar solvent and decalin as a nonpolar solvent are to examine the solvent effect on this reaction. The mixtures were heated at the low temperature of $80^{\circ} \mathrm{C}$ with stirring in a microwave reactor or in an oil bath. The microwave experiment was carried out using a single mode microwave apparatus (Green Motif II) operated at $300 \mathrm{~W}$ and $500 \mathrm{~W}$. The reaction was conducted under an argon gas atmosphere. The reaction mixtures were sampled at 2, 5, 20, and 40 minutes. After 60 minutes, the reaction mixtures were cooled to room temperature. The mixtures were then filtered and washed using ion-exchange water. When decalin was used as the solvent, the mixtures were extracted using methanol. 


\subsection{Kinetic Studies}

The reaction mixtures $\left(0.5 \mathrm{mmol}\right.$ substrate, 0.15 molar ratio $\mathrm{FeCl}_{3}$ catalyst and 7 $\mathrm{cm}^{3}$ of 1,2-dichloroethane) were reacted under the microwave irradiation conditions. At a specific time, a $0.1 \mathrm{~cm}^{3}$ sample was taken out by a syringe with a long needle. The reactions were performed at several temperatures of $50^{\circ} \mathrm{C}, 60^{\circ} \mathrm{C}$, $70^{\circ} \mathrm{C}$ and $80^{\circ} \mathrm{C}$.

\subsection{Measurement}

The ratio of the products was identified by High Performance Liquid Chromatography (HPLC) analysis using a Shimadzu LC-20A system equipped with a UV detector. An ODS column was used with methanol: water $(9: 1, \mathrm{v} / \mathrm{v})$ as the eluent. The structure of the products was confirmed by Nuclear Magnetic Resonance (NMR) and Gas Chromatography Mass Spectrometer (GC-MS) analysis. The NMR spectra were recorded by an FT-NMR ECS 400 (JEOL) at $400 \mathrm{MHz}$ $\left({ }^{1} \mathrm{H}\right)$ and room temperature in $\mathrm{CDCl}_{3}$. The molecular weight and mass fragmentation of the products were determined using a GC-MS QP5050A from Shimadzu. The ${ }^{1} \mathrm{H}-\mathrm{NMR}$ relaxation time was measured by the inversion-recovery method to investigate the molecular motion of the proton.

\section{Results and Discussion}

\subsection{Catalytic Effect of the $\mathrm{FeCl}_{3}$ Catalyst}

Initially, the Claisen rearrangement of the allyloxybenzene (1a) was investigated in the absence of the $\mathrm{FeCl}_{3}$ catalyst. As the result, the reaction could not take place without the $\mathrm{FeCl}_{3}$ catalyst at $80^{\circ} \mathrm{C}$ under microwave irradiation and no product was observed. In the presence of the $\mathrm{FeCl}_{3}$ catalyst, the reaction proceeded. Based on previous reports, the utilization of a metal catalyst induced a sequential reaction [10]. In this reaction using $\mathrm{FeCl}_{3}$, both a rearrangement (1b) and cyclization product (1c) were obtained. When 2-allylphenol (1b) was heated in the presence of the $\mathrm{FeCl}_{3}$ catalyst, 2-methylcoumaran (1c) was formed as the sole product.

The reaction mechanism was suggested through rearrangement of $1 \mathrm{a}$ affords $1 \mathrm{~b}$, followed by cyclization of $1 \mathrm{~b}$ leading to $1 \mathrm{c}$ (Scheme 1 ). It was postulated that $\mathrm{FeCl}_{3}$ catalyzed the rearrangement and cyclization reaction through coordination to the oxygen atom at the transition state. $\mathrm{FeCl}_{3}$ facilitated the reaction by causing an inductive effect that would effectively polarize the transition state. This interaction would decrease the activation energy so that the reaction could proceed at low temperature.<smiles>C=CCOc1ccccc1</smiles>

allyloxybenzene (1a)

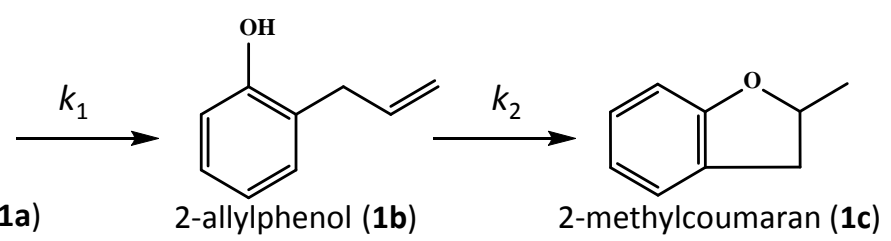

Scheme 1 . The rearrangement and cyclization reaction pathway. 
Before investigating the more complex structures, the kinetic behaviors of the reactions were studied. The decreasing amounts of $1 \mathrm{a}$ and increasing amounts of $1 \mathrm{c}$ were measured as a function of time at four different temperatures between $50^{\circ} \mathrm{C}$ and $80^{\circ} \mathrm{C}$ in 1,2-dichloroethane. The plots of the natural logarithms of the concentrations of $1 \mathrm{a}$ and $1 \mathrm{c}$ versus time at each temperature are shown in Figure 1 and Figure 2.

From Figure 1 and Figure 2, it is clear that the linear correlative coefficients are higher than 0.98 , which indicates that $\ln [\mathrm{A}]$ is proportional to the reaction time at different temperatures. It was showed that the reaction followed the first-order reaction. The measured rate constants were obtained from the slope values of the straight line and summarized in Table 1. Using the measured rate constants, the activation energy (Ea) could be obtained. The parameters of the Arrhenius equation are obtained from the relationship of the rate constant with the reaction temperature. The Arrhenius plot for the Claisen rearrangement of $1 \mathrm{a}$ and the cyclization reaction of $1 \mathrm{~b}$ are shown in Figure 3.

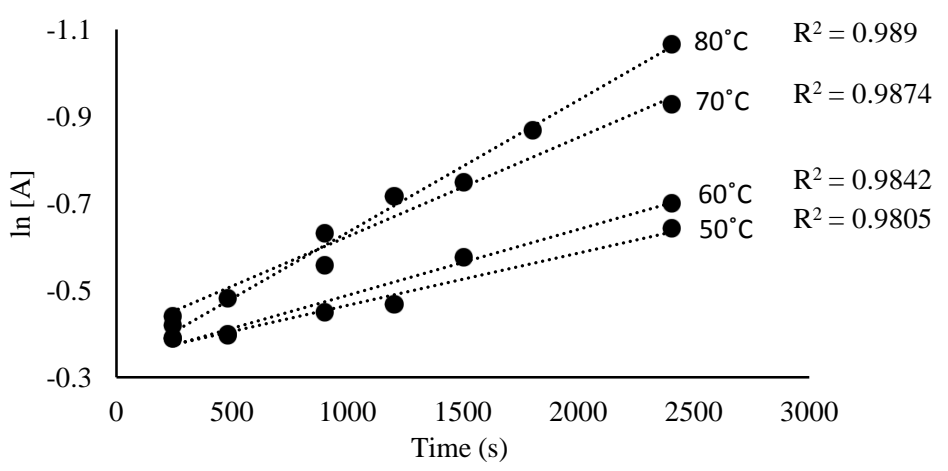

Figure 1. The decreasing concentration of $\mathbf{1 a}$ at different temperature.

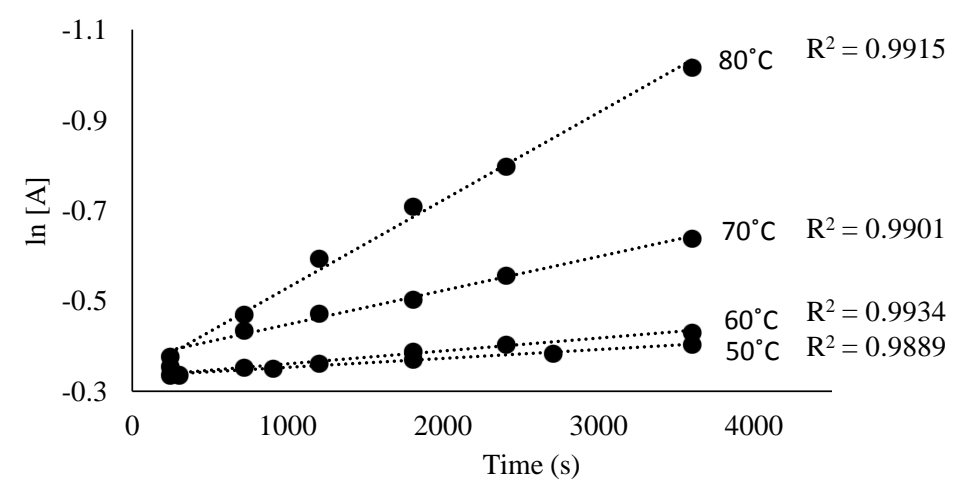

Figure 2. The increasing concentration of $1 \mathrm{c}$ at different temperature.

Table 1. The measured rate constants of $k_{1}$ and $k_{2}$ in several different temperatures.

\begin{tabular}{ccc}
\hline Temperature $\left({ }^{\circ} \mathrm{C}\right)$ & $k_{1} \times 10^{4}\left(\mathrm{~s}^{-1}\right)$ & $K_{2} \times 10^{4}\left(\mathrm{~s}^{-1}\right)$ \\
\hline 50 & 1.13 & 0.13 \\
60 & 1.51 & 0.28 \\
70 & 2.05 & 0.75 \\
80 & 2.96 & 1.93 \\
\hline
\end{tabular}




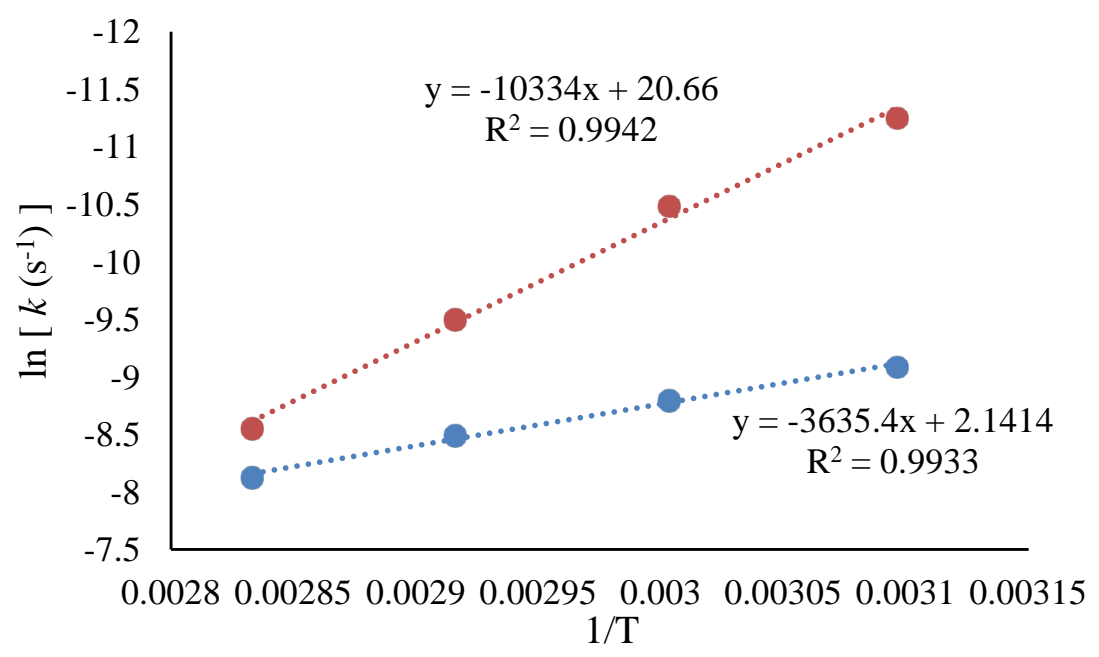

Figure 3. The Arrhenius plots of the Claisen rearrangement and the cyclization reaction in the presence of the $\mathrm{FeCl}_{3}$ catalyst (blue line: decreasing amounts of 1a, red line: increasing amounts of $1 \mathrm{c}$ ).

The Ea values of the rearrangement and cyclization reactions calculated from the slope were $30.22 \mathrm{~kJ} / \mathrm{mol}$ and $85.92 \mathrm{~kJ} / \mathrm{mol}$, respectively. The Ea value of the cyclization reaction was higher than that of the Claisen rearrangement reaction. The proposed energy profile showed that the cyclization reaction of $\mathbf{1 b}$ required a higher energy to proceed than the Claisen rearrangement reaction of 1a (Figure 4). Thus, it indicated that the rearrangement reaction is kinetically controlled and the cyclization reaction is thermodynamically controlled.

It was then necessary to determine if the reaction was proceeding through an intermolecular mechanism in which the substrate became fragmented into separate nuchleophilic and electrophilic species or through an intramolecular mechanism. Previously, our laboratory reported that naphthalene derivatives have an intermolecular rearrangement character [9]. Thus, we expanded the scope of the reaction with 1-allyloxynaphthalene (2a). The rearrangements of the naphthalene derivatives bearing a crotyloxy group (3a) and a cinnamyl group (4a) at the 1 position were also discussed. The products are shown in Table 2.

As the results, the main product of the reaction of $3 \mathrm{a}$ and $4 \mathrm{a}$ were the intramolecular rearranged one even in the presence of $\mathrm{FeCl}_{3}$. The intermolecular rearranged product was not observed in the reaction mixtures. This clearly showed that the reaction occurs through the intramolecular mechanism and not the intermolecular mechanism. The authors also reported the use of a crotyloxy group in the aromatic Claisen rearrangement, which is not a well-known starting material for the aromatic Claisen rearrangement unlike the cinnamyloxy group. The product yields of $\mathbf{3 a}$ were higher than those of $1 \mathrm{a}$ and $\mathbf{2 a}$, however, the dehydrogenation product (3d) was formed. The methyl substituent acts as an electron donating group, thus enhancing the electron density of the carbon atom where the formation of new bond will take place. Therefore, the yield increased for the reaction of 3a. In this case, the additional methyl substituent on the allyl moiety also leads to the dehydrogenation reaction of the coumaran derivatives. 
Table 2. The rearrangement and the cyclization products of allyloxyarene derivatives.

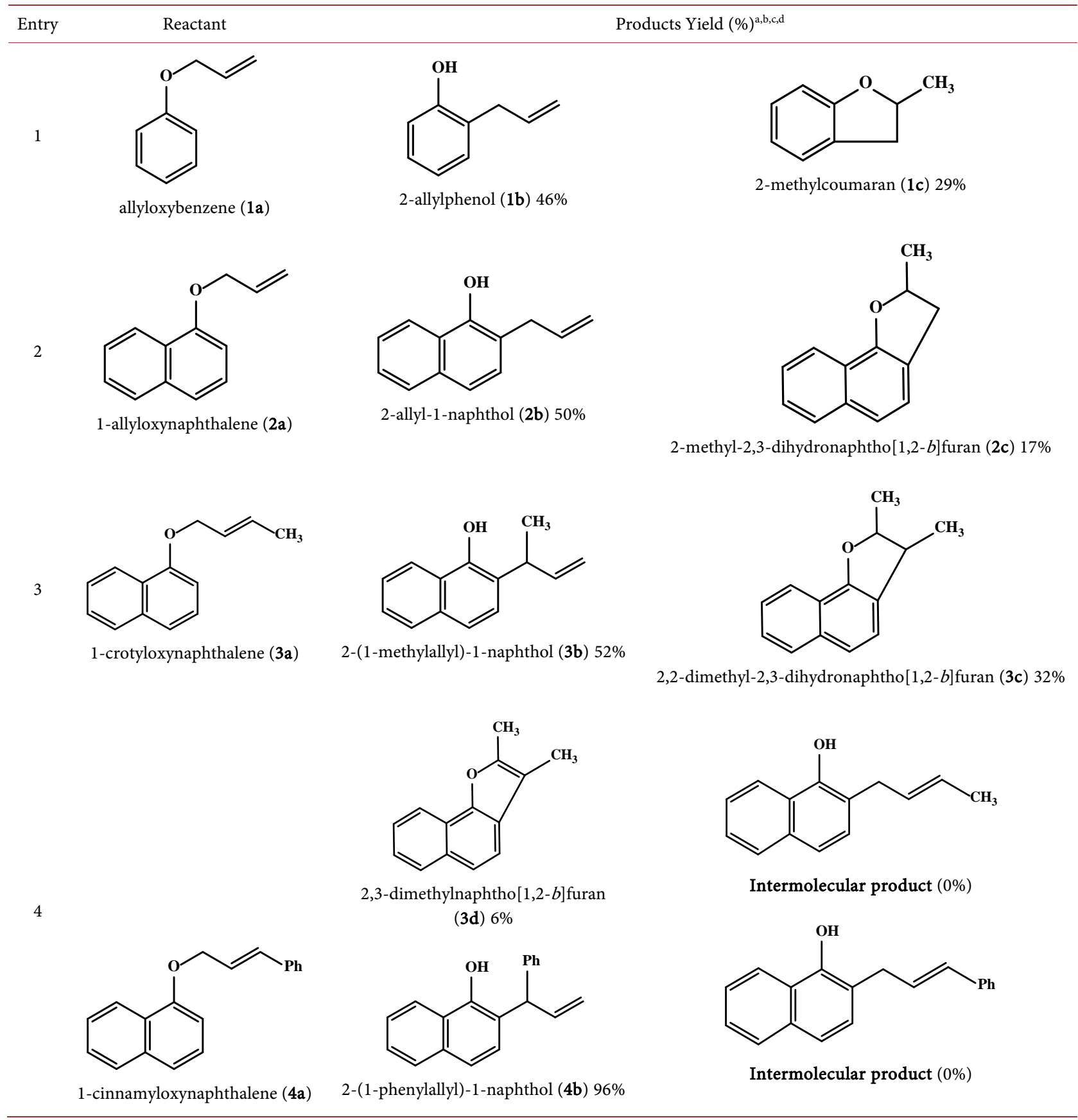

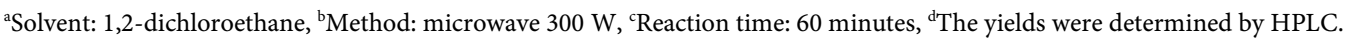

Interestingly, the reaction of $4 \mathrm{a}$ only produced $\mathbf{4 b}$ as the main product in an excellent yield. The cyclization product was not formed in the reaction of $4 \mathrm{a}$. On the other hand, our previous studies showed that the para-rearranged product is accelerated for cinnamyloxyarene derivatives. Because the stable conformation for the cinnamyloxyarene derivatives, in which the $\mathrm{C}-\mathrm{C}$ double bond is near the naphthalene ring and the phenyl group is situated away from the naphthalene ring, is easily converted in the transition state to the para-rearranged product [9] [11]. 


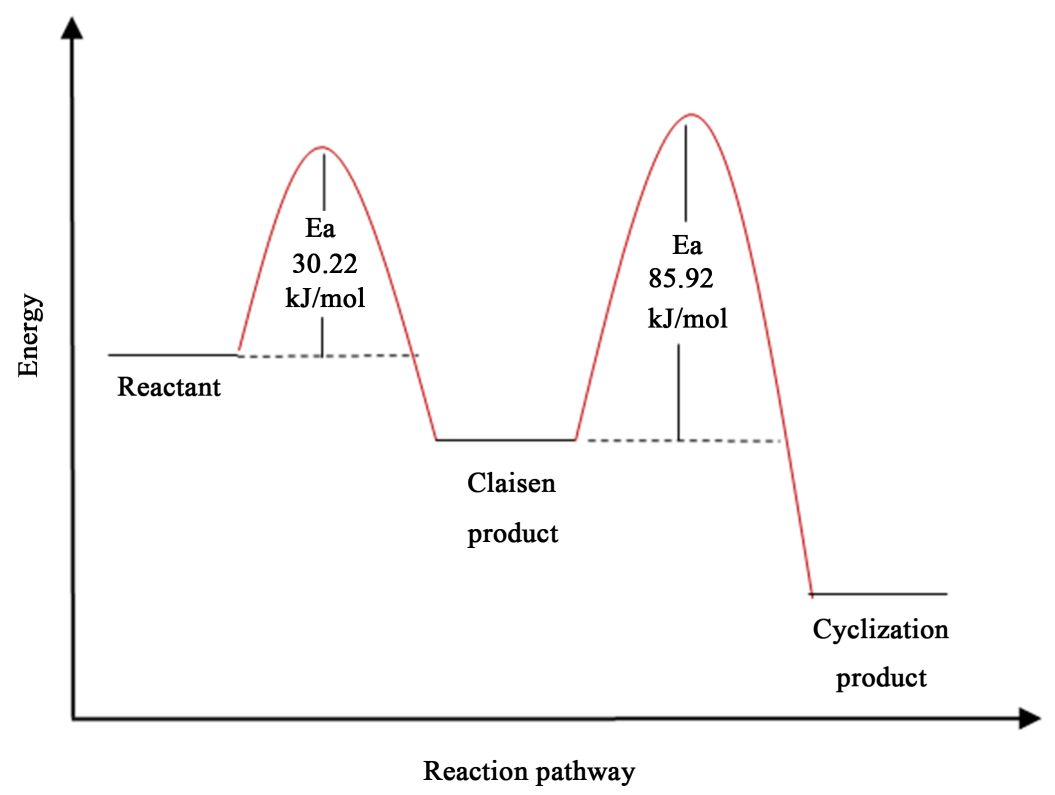

Figure 4. The proposed schematic energy profile of the catalysis sequential reaction.

In this study, we suggested that the phenyl ring blocked the binding site between the oxygen atom and the double bond during the reaction. As shown in Figure $5, \mathrm{FeCl}_{3}$ has the possibility to interact with the phenyl ring besides coordinating with the oxygen atom. Since the aromatic ring is an electron-rich $\pi$ system, $\mathrm{Fe}^{3+}$ as a metal cation is able to interact with the aromatic ring. Thus, the cyclization reaction did not occur and the para-rearranged product was not formed due to the opposite conformation of the $\mathrm{C}-\mathrm{C}$ double bond. Hence, the ortho-rearranged product would remain as the sole product.

The spin-lattice relaxation time $\left(T_{1}\right)$ can be used to determine the conformational preference of the molecules [12]. Therefore, the ${ }^{1} \mathrm{H}-\mathrm{NMR}$ relaxation time study was conducted to investigate the molecular motion of the proton. The $T_{1}$ of the proton at the $\mathrm{C}_{3}$ position was measured, since the $\mathrm{C}_{3}$ proton should be influenced by the motion of the substituents in the allyl group. The results are shown in Figure 6.

Based on these results, the $T_{1}$ of the $\mathrm{C}_{3}$ proton of $4 \mathrm{~b}$ was determined to be 9.66 s. This $T_{1}$ value is higher compared to those of the other two substrates. The high $T_{1}$ suggested that the $\mathrm{C}_{3}$ proton has a high mobility and the phenyl group lies away from the $\mathrm{C}_{3}$ proton. In the case of $3 b$, the rotation around the $\mathrm{C}_{2}-\mathrm{C} \gamma$ bond axis hinders the motion of the $\mathrm{C}_{3}$ proton, thus the relaxation time would be short.

\subsection{Microwave Irradiation Effect}

In this study, the comparison between the microwave irradiation and oil bath heating for the Claisen rearrangement reaction of allyloxyarenes is discussed. The results are summarized below in Figure 7 and Figure 8.

As can be seen in Figure 7, the accelerating effect during microwave irradiation was observed for substrates $\mathbf{2 a}$ and $\mathbf{4 a}$ in decalin. Especially for product $\mathbf{4 b}$, 


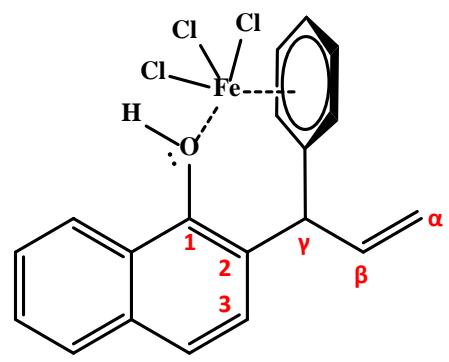

Figure 5. The proposed interaction between $\mathrm{FeCl}_{3}$ and 2-(phenylallyl)-1-naphthol (4b).<smiles>C=CCc1c([18O])cc2ccccc2c1O</smiles><smiles></smiles><smiles>C=CC(c1ccccc1)c1cc2ccccc2cc1O</smiles>

Figure 6. The $T_{1}$ data of the $\mathrm{C}_{3}$ proton in the several substrate.

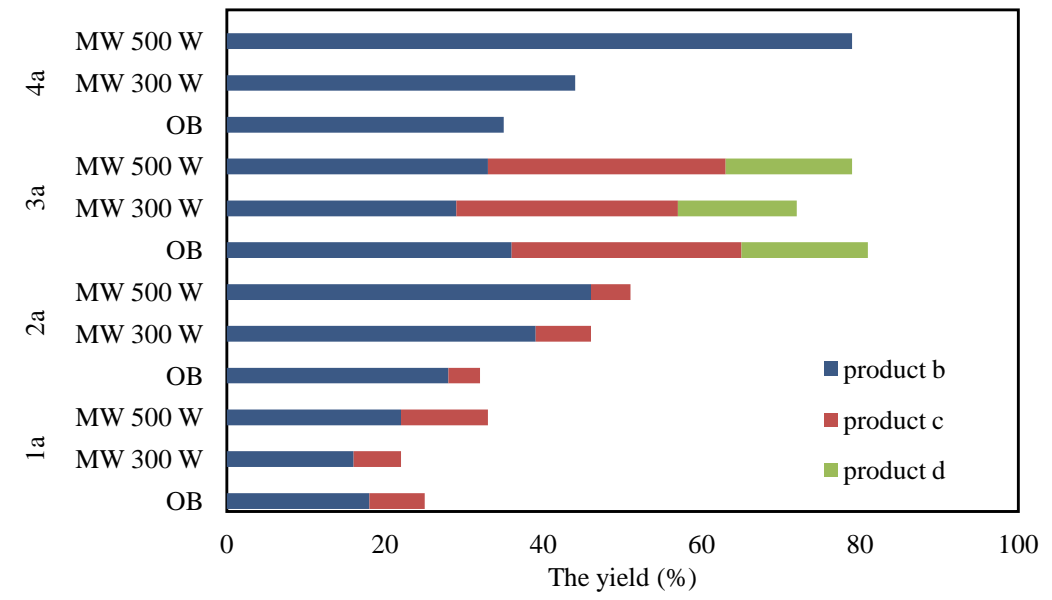

Figure 7. The yields of products $b$ and $c$ in decalin solvent ${ }^{\mathrm{a}, \mathrm{b}} .{ }^{\mathrm{a}}$ temperature: $80^{\circ} \mathrm{C}$, ${ }^{\mathrm{b}}$ reaction time: 60 minutes (MW: microwave and OB: oil bath).

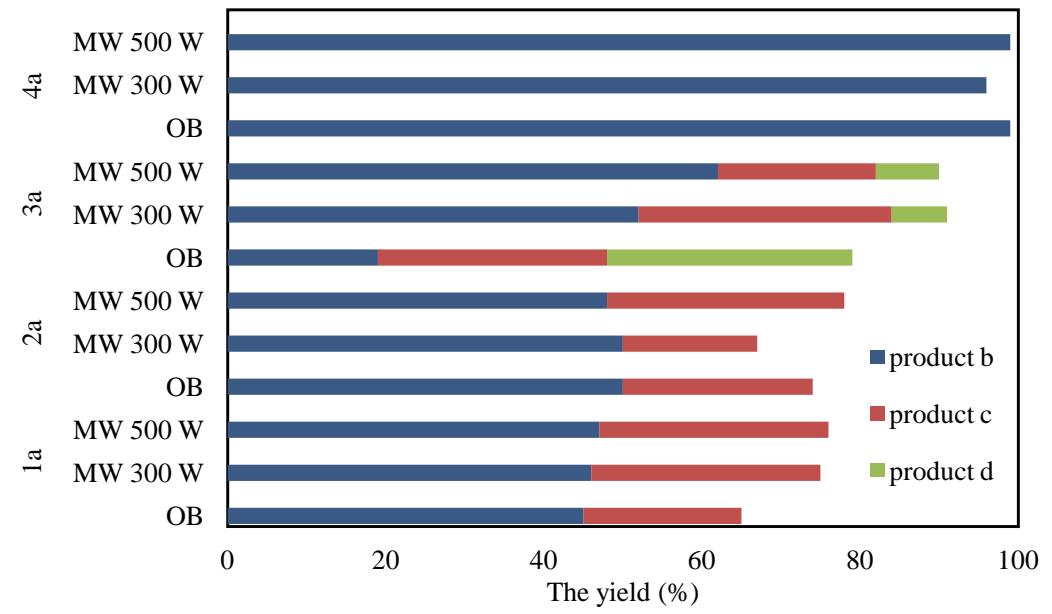

Figure 8. The yields of products $\mathbf{b}$ and $\mathbf{c}$ in 1,2-dichloroethane solvent ${ }^{\mathrm{a}, \mathrm{b}}$. ${ }^{\mathrm{a}}$ temperature:

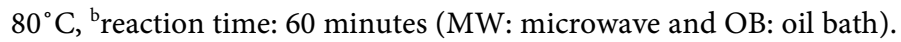


the yield from the microwave $500 \mathrm{~W}$ is double that for the oil bath heating. This would be due to the fact that decalin is a nonpolar solvent which does not absorb the microwaves, so the accelerating effect occurs on the polar substrates. However, the microwave accelerating effect was not observed in the Claisen rearrangement of 3a. The additional methyl substituent which attribute to the high reactivity might shade the microwave effect. In the case of $1 \mathrm{a}$ reaction, an increase in the microwave power was necessary to increase the product yields. Since decalin has a low dielectric constant, thus a higher energy to promote the reaction during the microwave irradiation was required.

1,2-Dichloroethane has a low polarity compared to decalin. Based on a previous report, the Claisen rearrangement is accelerated by a more polar solvent, because the transition state, in which the oxygen atom has a higher electron density, is stabilized by the coordination of the solvent [13]. As a consequence, the reaction yields would be higher than in decalin. However, such a solvent more efficiently absorbs the microwaves, so increasing the microwave power did not significantly affect the yields in the 1,2-dichroloethane (Figure 8). Interestingly, in the Claisen rearrangement reaction of $3 a$, oil bath heating afforded higher yield in the dehydrogenation product (3d) instead lower yields of the Claisen rearranged product ( $3 \mathbf{b})$.

The temperature change in the reaction system under microwave irradiation was found. The substrates $1 \mathbf{a}$ and $\mathbf{2} \mathbf{a}$ were dissolved in the solvent and irradiated by the microwave. Then temperature versus microwave irradiation time was measured at the same conditions for the reaction system. The results are shown in Figure 9 and Figure 10. In the presence of the $\mathrm{FeCl}_{3}$ catalyst, the temperature increased faster than in the absence of $\mathrm{FeCl}_{3}$ catalyst; the substrate alone exists in decalin or 1,2-dichloroethane. These results indicated that the microwave energy is absorbed by an active species in the reaction mixture. This suspected active species is the adduct between the substrate and $\mathrm{FeCl}_{3}$ catalyst. $\mathrm{FeCl}_{3}$ as a Lewis acid would forms a complex with the aromatic ring as shown in Figure 11. The

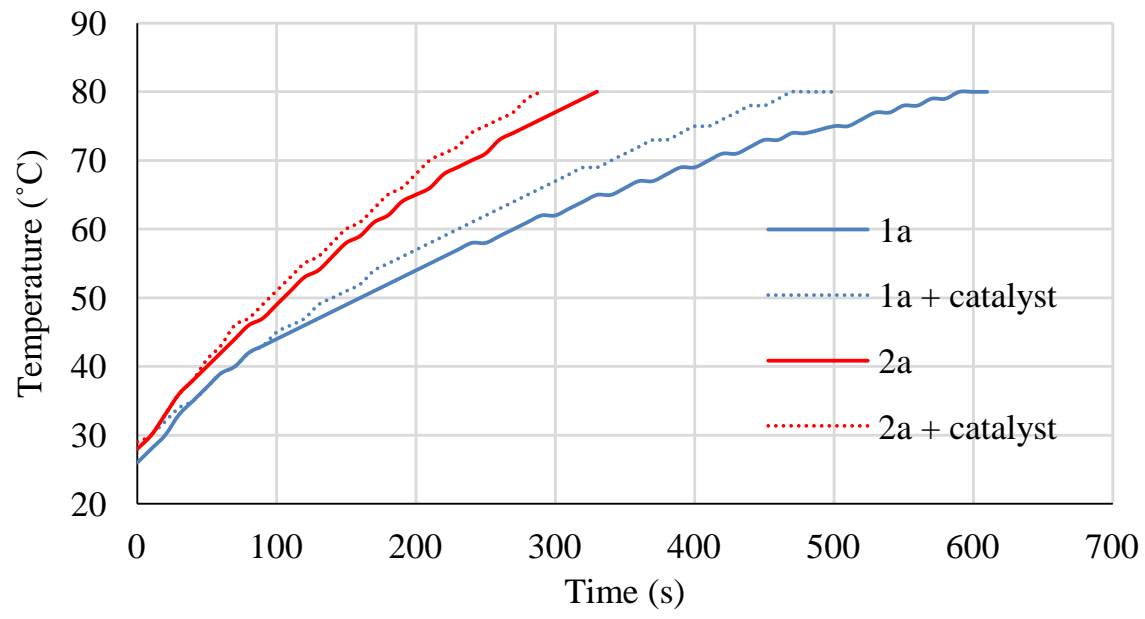

Figure 9. The temperature versus irradiation time plot of the substrate $1 \mathrm{a}, 2 \mathrm{a}$ and $\mathrm{FeCl}_{3}$ catalyst under microwave irradiation in decalin. 
complex species was expected to efficiently absorb the microwaves and affected the temperature. The high temperature in the micro region around the species would influence the acceleration effect during the microwave heating reaction.

\section{3. ${ }^{1} \mathrm{H}-\mathrm{NMR}$ Relaxation Time}

Based on a ${ }^{1} \mathrm{H}-\mathrm{NMR}$ relaxation time study, the expected formation of the ferric-arenes complex was elucidated. Generally, shortening of the proton relaxation time indicates a decreasing of the mobility of the proton [14]. As shown in Table 3, in the presence of the $\mathrm{FeCl}_{3}$ catalyst, the relaxation times of 1a and 2a became shorter than that for no $\mathrm{FeCl}_{3}$ catalyst. In this case, the aromatic rings of 1a and $2 \mathrm{a}$ interacted with the $\mathrm{Fe}^{3+}$ and formed a complex. The species have a larger volume, thus they more slowly rotate. Consequently, the mobility of the proton in the aromatic ring would be reduced. In non-aromatic substrates, e.g., cyclohexane and decalin, such a decrease in $T_{1}$ did not occur. This means that $\mathrm{FeCl}_{3}$ does not interact with the cyclic ring of cyclohexane and decalin.

Table 3. The ${ }^{1} \mathrm{H}-\mathrm{NMR}$ relaxation time data $\left(T_{1}\right)$.

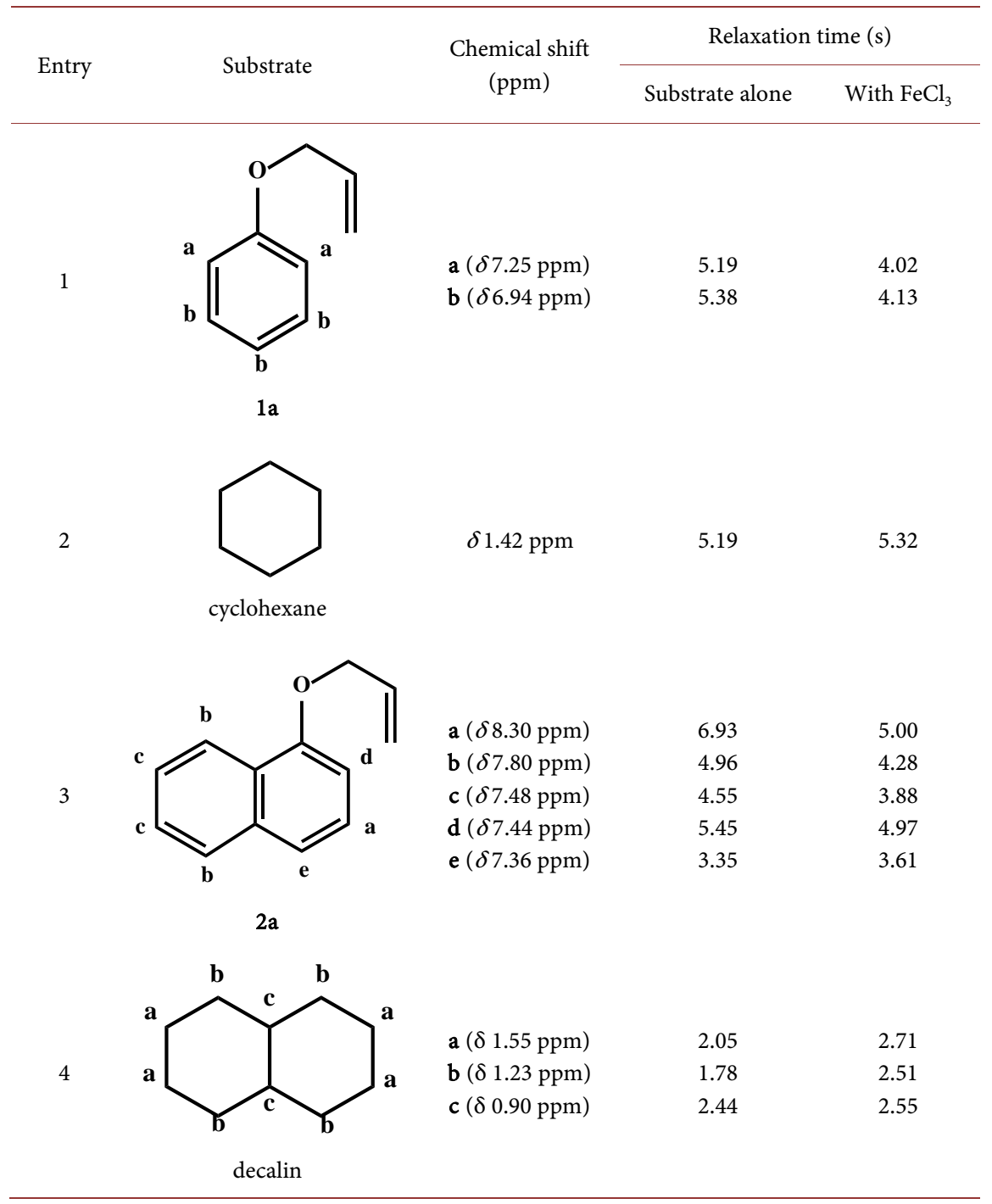




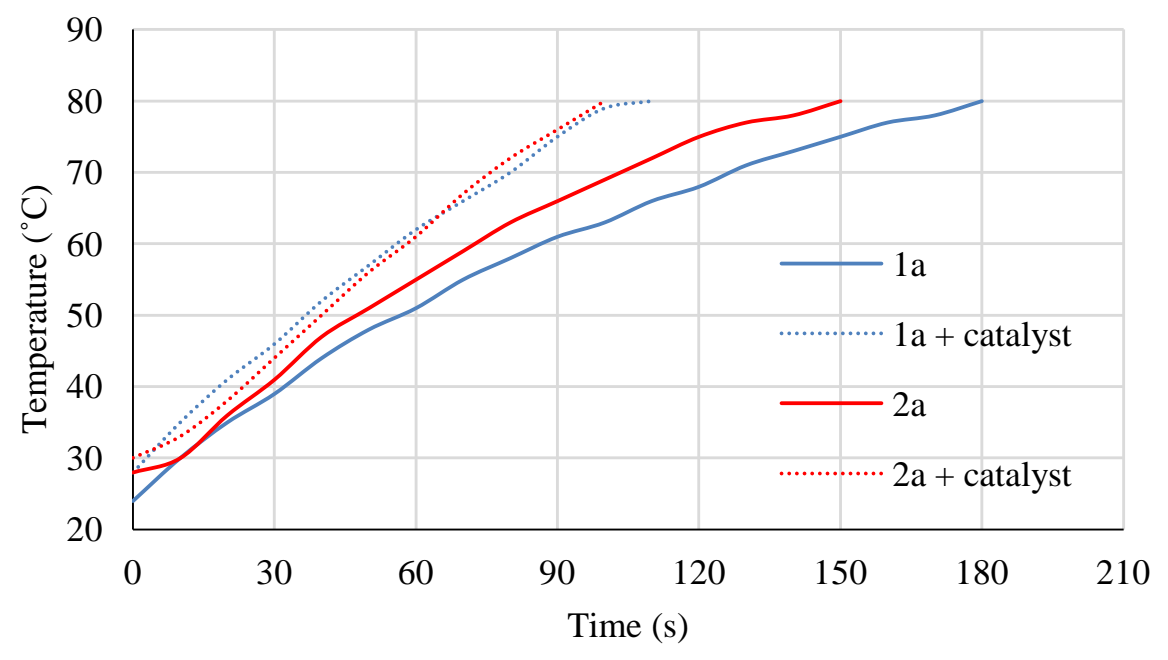

Figure 10. The correlation between temperature and time under microwave irradiation in decalin.

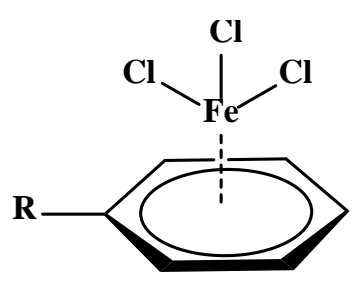

Figure 11. The complex of the ferric-arenes.

\section{Conclusion}

In this study, the combination of the $\mathrm{FeCl}_{3}$ catalyst and microwave irradiation allows the reactions to occur under milder reaction conditions. The $\mathrm{FeCl}_{3}$ catalyst is able to initiate the Claisen rearrangement reaction of allyloxyarenes at the low temperature of $80^{\circ} \mathrm{C} . \mathrm{FeCl}_{3}$ coordinates on the etheral oxygen to reduce the transition state energy. The reaction occurs through an intramolecular mechanism, not the intermolecular one, even in the presence of the $\mathrm{FeCl}_{3}$ catalyst. The microwave accelerating effect was observed and it was affected by the type of solvent. Furthermore, the formation of the complex ferric-arenes, which were expected to efficiently absorb microwaves, was confirmed. For the rearrangement of cinnamyloxynaphthalene (4a), $\mathrm{FeCl}_{3}$ coordinates on both the oxygen and the phenyl ring. This structure would efficiently absorb the microwaves as well as reduce the energy of the transition state. Namely, the active species of the Claisen rearrangement efficiently absorbs the microwaves. Finally, the authors expect that these findings can offer such an environment-friendly reaction which leads to the green chemistry reaction.

\section{References}

[1] Castro, A.M.M. (2004) Claisen Rearrangement over Past Nine Decades. Chemical Reviews, 104, 2939-3002. https://doi.org/10.1021/cr020703u

[2] Grant, V.G. and Liu, B. (2005) Iridium(III)-Catalyzed Tandem Claisen Rearrangement-Intramolecular Hydroarylation of Aryl Allyl Ethers to Form Dihydrobenzo- 
furans. Tetrahedron Letters, 46, 1237-1239.

https://doi.org/10.1016/j.tetlet.2005.01.006

[3] Hiersemann, M. and Abraham, L. (2001) The $\mathrm{Cu}(\mathrm{OTf})_{2}$ - and $\mathrm{Yb}(\mathrm{OTf})_{3}$-Catalyzed Claisen Rearrangement of 2-Alkoxycarbonyl-Substituted Allyl Vinyl Ether. Organic Letters, 3, 49-52. https://doi.org/10.1021/ol006760w

[4] Lambert, T.H. and MacMillan, D.W.C. (2002) Development of A New Lewis AcidCatalyzed [3,3]-Sigmatropic Rearrangement: The Allenoate-Claisen Rearrangement. Journal of American Society, 124, 13646-13647. https://doi.org/10.1021/ja028090q

[5] Gay, R.M., Manarin, F., Schneider, C.C., Barancelli, D.A., Costa, M.D. and Zeni, G. (2010) $\mathrm{FeCl}_{3}$-Diorganyl Dichalcogenides Promoted Cyclization of 2-Alkynylanisoles to 3-Chalcogen Benzo[b]furans. Journal of Organic Chemistry, 75, 5701-5706. https://doi.org/10.1021/jo101126q

[6] Roesky, H.W. and Kennepohl, D.K. (2009) Experiment in Green and Sustainable Chemistry. Wiley-VCH, Weinheim.

[7] Nushiro, K., Kikuchi, S. and Yamada, T. (2013) Microwave Effect on Catalytic Enantioselective Claisen Rearrangement. Chemical Communication, 49, 8371-8373. https://doi.org/10.1039/c3cc44610g

[8] Hoz, A., Diaz-Ortiz, A. and Moreno, A. (2005) Microwave in Organic Synthesis; Thermal and Non-Thermal Microwave Effects. Chemical Society Reviews, 34, 164-178. https://doi.org/10.1039/B411438H

[9] Okada, Y. and Imanari, D. (2012) Claisen and Intermolecular Rearrangement of Cinnamyloxynaphthalene. International Journal of Organic Chemistry, 2, 38-43. https://doi.org/10.4236/ijoc.2012.21007

[10] Hiersemann, M. and Nubbemeyer, U. (2007) The Claisen Rearrangement: Methods and Applications. Wiley-VCH, Weinheim. https://doi.org/10.1002/9783527610549

[11] Okada, Y., Adachi, M. and Hayashi, T. (2002) Substituent Effect on Claisen Rearrangement of 1-Substituted 2-Cinnamyloxybenzenes. Journal of Oleo Science, 51, 359-364. https://doi.org/10.5650/jos.51.359

[12] Chazin, W.J. and Colebrook, L.D. (1986) A Proton Spin-Lattice Relaxation Pathway Analysis of Conformational Preferences of Aryl and Enol Ethers in Some Cinchoma and Morphine Alkaloids. Canadian Journal of Chemistry, 64, 2220-2224. https://doi.org/10.1139/v86-365

[13] Okada, Y. and Ozaki, F. (2011) Solvent Effect for Microwave-Assisted Claisen Rearrangement of Allyloxybenzene. Proceedings of the 13 th International Conference on Microwave \& High Frequency Heating. Toulouse, 5-7 September 2011, 69-72.

[14] Arimura, T., Ide, S., Nishioka, T., Kumamoto, S., Murata, S. and Tachiya, M. (2004) ${ }^{1} \mathrm{H}-\mathrm{NMR}$ Relaxation Time Studies of Molecular Motions in a 1,3-Alternate-Shaped Calix[4]arene Ensemble. Journal of Oleo Science, 53, 275-278.

https://doi.org/10.5650/jos.53.275 
Submit or recommend next manuscript to SCIRP and we will provide best service for you:

Accepting pre-submission inquiries through Email, Facebook, LinkedIn, Twitter, etc. A wide selection of journals (inclusive of 9 subjects, more than 200 journals)

Providing 24-hour high-quality service

User-friendly online submission system

Fair and swift peer-review system

Efficient typesetting and proofreading procedure

Display of the result of downloads and visits, as well as the number of cited articles Maximum dissemination of your research work

Submit your manuscript at: http://papersubmission.scirp.org/

Or contact gsc@scirp.org 